\title{
Cochrane schizophrenia reviews influence on policy and practice: an earthquake zone
}

\author{
C. E. Adams* \\ Coordinating Editor Cochrane Schizophrenia Group, Chair of Mental health Services Research, Division of Psychiatry, university of Nottingham, \\ Nottingham, UK
}

Policymaking and the care of people with schizophrenia are still recovering from the shock of the arrival of a more objective way of appraising the best available evidence. It is still early days. There are several directions that practice and policy could go and there are indications that the rebuilding is not the same as what has gone before. After the earthquake we should be able to build more wisely.

Key words: Randomised controlled trial, schizophrenia, systematic reviews.

Twenty years ago, policy and practice largely rested on the opinion of experts whose recourse to evidence was to support their pre-formed views (Lau et al. 1992). In many cases, through wisdom and experience and an appraisal of the literature, these opinions may well have been correct. However, the opinion of experts, and even deeply entrenched practices and policies, has been shown to be contrary to the best available evidence (Lau et al. 1992). Much earlier than 20 years ago, pioneers working in the field of pregnancy and childbirth began to methodically collect the best available evidence, summarise it and maintain systematically produced and electronically disseminated reviews (Chalmers et al. 1993). The Oxford Database of Perinatal Trails was ground-breaking and cleared the way for the seismic shift that became evident across healthcare during the 1990s. Without the work of this sub-specialty the Cochrane Collaboration would not be in existence.

In the early 1990s, the Cochrane Collaboration, largely funded through government sources, challenged those working in healthcare to put policy and practice on a footing of strong, objective, critically appraised and synthesised evidence (Chalmers et al. 1993; Silagy, 1993). Answering this call, specialty by sub-specialty, resulted in polarisation. Many were hostile to the whole argument, deeply uncomfortable with the anachronistic possibilities and concerned that there was going to be dictation of care by thoughtless use of numbers

* Address for correspondence: Professor C. E. Adams, Coordinating Editor Cochrane Schizophrenia Group, Chair of Mental Health Services Research, Division of Psychiatry, Gateway Building, Jubilee Campus, University of Nottingham Innovation Park, Triumph Road, NG7 2TU, UK

(Email: clive.adams@nottingham.ac.uk)
(Clinicians for the Restoration of Autonomous Practice (CRAP) Writing Group, 2002). These concerns were despite every effort of those truly working in the field reassuring clinicians and policy makers that evidencebased medicine was the judicious use of best evidence, and that objective appraisal of evidence should go hand in hand with clinical wisdom (Sackett, 1997). Scaremongers, partly aided by some high priests of evidence-based medicine (Adams \& Gilbody, 2001), continued to cause many clinicians and policy makers to shy away from changing practice. But the earth had moved under the feet of all of us and was beginning to settle into a recognisable but different form.

This shift underfoot had occurred worldwide through the corridors of McMaster's Medical School in Canada, to the School of Medicine and Public Health, University of Newcastle, Australia and the work of the National Perinatal Epidemiology Unit and Clinical Trials Service Unit in Oxford, UK. After such a quake rebuilding was necessary. The Centre for Reviews and Dissemination in York began to provide summaries of best evidence for both policy makers and practitioners and produced Effectiveness Bulletins - forerunners for what was to become technology appraisals for NICE in the United Kingdom. Effectiveness Bulletins for care of people with schizophrenia were published in 1999 (Centre for Reviews and Dissemination, York, UK, 1999) and 2000 (Centre for Reviews and Dissemination, York, UK, 2000) and were largely well received. However, phrases that now seem banal such as 'newer "atypical" antipsychotics may be a further refinement, but not a revolution, in the care of those with schizophrenia' triggered strong antagonistic reactions from those more used to writing subjective guidance who had not realised 
what a shift had occurred in the landscape. Now, over a decade later, the systematic approach - or at least the reference to the systematic approach - suffuses policy documents, guidelines, teaching texts and both research and applications for research. For example, in the UK major fund givers will not provide support to evaluate studies unless the application includes evidence from a relevant systematic review.

It is, however, a fact that we are not standing on the bright sunlit uplands of evidence-based practice for people with schizophrenia. In the second decade of the 21st century we still stumble amidst rubble of the upheaval. Enormous progress has been made but there are considerable hindrances that impede a full rebuild. Cochrane largely produces long complex reviews that shine light on the grey state of current evidence. Rarely (at least in the case of schizophrenia) is evidence black and white. Policy makers may not feel entirely comfortable with the complex messages of Cochrane reviews and may prefer information supplied in a different format. Until recently, Cochrane has ignored this need. Clinicians, confronted with the practical reality of treating patients on a day-to-day basis and the complexity of Cochrane reviews chose more condensed palatable forms of information that may bear little relationship to high-grade evidence. Initially those making guidelines in the UK (at least), although reacting to the seismic shift of the need for good evidence, were over influenced by those so wedded to numbers within reviews as to forget clinical meaning. Further undermining the rebuilding of a thoughtful healthcare landscape is researchers' intransigence regarding clinically meaningful study design. It is hard for a Cochrane review to have real impact when it is based on trials recruiting people rarely seen in daily practice, evaluating rigid treatments, recording outcomes of dubious clinical utility from which there is (understandable) enormous attrition in a matter of a few weeks (Thornley \& Adams, 1998).

So are we condemned for the next decade to wander in the wreckage? Certainly, there are those who wish to rebuild in the image of the old. For example, within the UK the enormous progress made through NICE has been undermined by recent developments by which this body has had its directive powers reduced (Briggs, 2010). On the other hand, there are many important initiatives underway by which Cochrane reviews become more influential. Inclusion of GRADE summaries (Guyatt et al. 2011) in Cochrane reviews has many shortcomings but is a major progress and will facilitate the influence of Cochrane reviews especially for policy makers. For example, a large series of Cochrane schizophrenia review GRADE Summary of Findings files have been produced from Cochrane reviews to facilitate the new WHO guidance of the care of people with schizophrenia. Clinicians do need better access to Cochrane evidence and much effort has already been invested in this area. For example, Duodecim in Finland (Duodecim, 2011) is linking best evidence from Cochrane reviews to individual patient records. Those producing guidelines within the UK have greatly improved their product, certainly for schizophrenia. The powerful influence of consumers, which has ensured much more clinically meaningful guidance, is now produced fitting in with the pathways that people with schizophrenia take throughout the life-course of the illness. Further initiatives such as Map of Medicine (Health Guidelines, Department of Health, 2011) afford opportunities of aligning Cochrane evidence with interactive interfaces for policy makers, commissioners, clinicians and recipients of care. Initiatives are underway to do just this for Cochrane schizophrenia reviews. Problem-based teaching has progressed over the last few decades although it is in danger of slipping back into more traditional didactic approaches. Bringing critical appraisal into the workplace is still too rare.

So, there remains much work to rebuild something better. Many Cochrane schizophrenia reviews have been too broad ranging and not nearly as clinically orientated as they should have been. It is now fundamental that those undertaking Cochrane reviews consider evidence from the prospective of the life-course of the illness. For example, it may be of interest that drug $X$ or psychological intervention $Y$ produces an effect for people with schizophrenia. It is, however, of more clinical value to know if drug $X$ is useful for people in their early stages of schizophrenia whereas psychological intervention $\mathrm{Y}$ has considerable effect later on in the illness (when drug $X$ is less effective). Although a bird's eye view of evidence is useful, it is of great utility to have information readily available for the clinical stage (prodromal, early, first episode, late), state (acute, stable) or specific clinical problem (negative symptoms, depression, aggression) that the person with schizophrenia currently suffers from. The next decade will see Cochrane reviews reconstructed to fit the needs of clinicians and recipients of care and those mapping the illness.

Probably because the landscape has genuinely changed the often less-than-attractive messages of imperfect Cochrane reviews have had considerable influence. Cochrane reviews are still better than most of what else is available and always, uniquely, are able to be corrected when criticism is valid. There is, however, much rebuilding to do both inside Cochrane and without. It is important that what we build is stronger for foundations of useful evidence 
rather than recreate the impermanent edifices of past times.

\section{Acknowledgements}

I would like to thank Dr Graeme Tosh (East Midlands Workforce Deanery, Nottingham, UK), Sam Roberts (University of Nottingham), Mark Fenton (NICE, UK) and Professor Maritta Valimaki (Department of Nursing Science, University of Turku, Finland) for advice on the manuscript.

\section{Conflicts of Interest}

CEA is Co-ordinating Editor of a Cochrane Group.

\section{References}

Adams CE, Gilbody S (2001). 'Nobody ever expects the Spanish Inquisition' (Python, 1991). Psychiatric Bulletin 25, 291-292.

Briggs H (2010). BBC News - NICE to lose powers to decide on new drugs. Retrieved 6 January 2011, from http://www. bbc.co.uk/news/health-11664684

Centre for Reviews and Dissemination, York, UK (1999).

Drug treatments for schizophrenia. Effective Health Care 5

(6), 1-12. Available at: http://www.york.ac.uk/inst/crd/ EHC/ehc56.pdf

Centre for Reviews and Dissemination, York, UK (2000). Psychosocial interventions for schizophrenia. Effective
Health Care 6(3), 1-8. Available at: http://www.york.ac.uk/ inst/crd/EHC/ehc63.pdf

Chalmers I, Enkin M, Keirse MJ (1993). Preparing and updating systematic reviews of randomized controlled trials of health care. The Milbank Quarterly 71, 411-437.

Clinicians for the Restoration of Autonomous Practice (CRAP) Writing Group (2002). EBM: unmasking the ugly truth. British Medical Journal 325, 1496-1498.

Duodecim (2011). The Finnish Medical Society Duodecim. Retrieved 6 January 2011, from http://www.duodecim.fi/ web/english/home

Guyatt G, Oxman AD, Akl EA, Kunz R, Vist G, Brozek J, Norris S, Falck-Ytter Y, Glasziou P, Debeer H, Jaeschke R, Rind D, Meerpohl J, Dahm P, Schünemann HJ (2011). GRADE guidelines 1. Introduction-GRADE evidence profiles and summary of findings tables. Journal of Clinical Epidemiology 64, 383-394.

Health Guidelines, Department of Health (2011). The Map of Medicine - England \& Wales. Retrieved 6 January 2011, from http://healthguides.mapofmedicine.com/choices/map/ schizophrenia2.html

Lau J, Antman EM, Jimenez-Silva J, Kupelnick B, Mosteller F, Chalmers TC (1992). Cumulative meta-analysis of therapeutic trials for myocardial infarction. New England Journal of Medicine 327, 248-254.

Sackett DL (1997). Evidence-based medicine. Seminars in Perinatology 21, 3-5.

Silagy C (1993). Randomised controlled trials: the challenge of Archie Cochrane. Medical Journal of Australia 158, 656-657.

Thornley B, Adams CE (1998). Content and quality of 2000 controlled trials in schizophrenia over 50 years. British Medical Journal 317, 1181-1184. 